\title{
Supplementary Data III
}

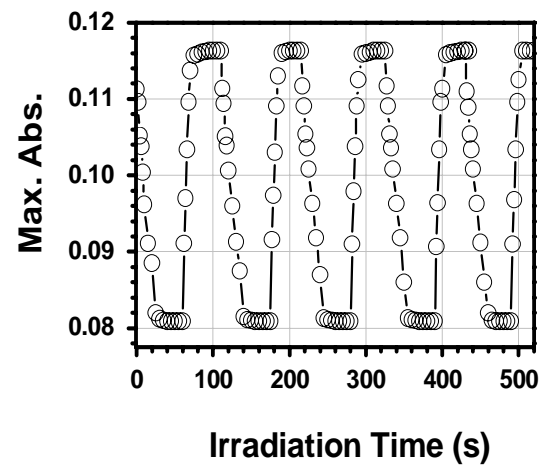

Figure. Fully-reversible $\mathrm{E} / \mathrm{Z}$ and $\mathrm{Z} / \mathrm{E}$ photoisomerization cycle induced on a multilayer film comprising $10 \mathrm{PNA} / \mathrm{CAG}$ bilayers by irradiating alternately UV (360 nm, P=2 $\left.\mathrm{mW} / \mathrm{cm}^{2}\right)$ and visible light $\left(100 \mathrm{~mW} / \mathrm{cm}^{2}\right)$. 